This item was submitted to Loughborough's Research Repository by the author.

Items in Figshare are protected by copyright, with all rights reserved, unless otherwise indicated.

\title{
Micro-Raman spectroscopy of indentation induced phase transformation in nanozirconia ceramics
}

PLEASE CITE THE PUBLISHED VERSION

http://dx.doi.org/10.1179/1743676110Y.0000000016

PUBLISHER

Maney Publishing (@ Institute of Materials, Minerals and Mining)

VERSION

AM (Accepted Manuscript)

LICENCE

CC BY-NC-ND 4.0

REPOSITORY RECORD

Paul, Anish, Bala Vaidhyanathan, and J.G.P. Binner. 2011. "Micro-raman Spectroscopy of Indentation Induced Phase Transformation in Nanozirconia Ceramics". figshare. https://hdl.handle.net/2134/8538. 
This item was submitted to Loughborough's Institutional Repository (https://dspace.lboro.ac.uk/) by the author and is made available under the following Creative Commons Licence conditions.

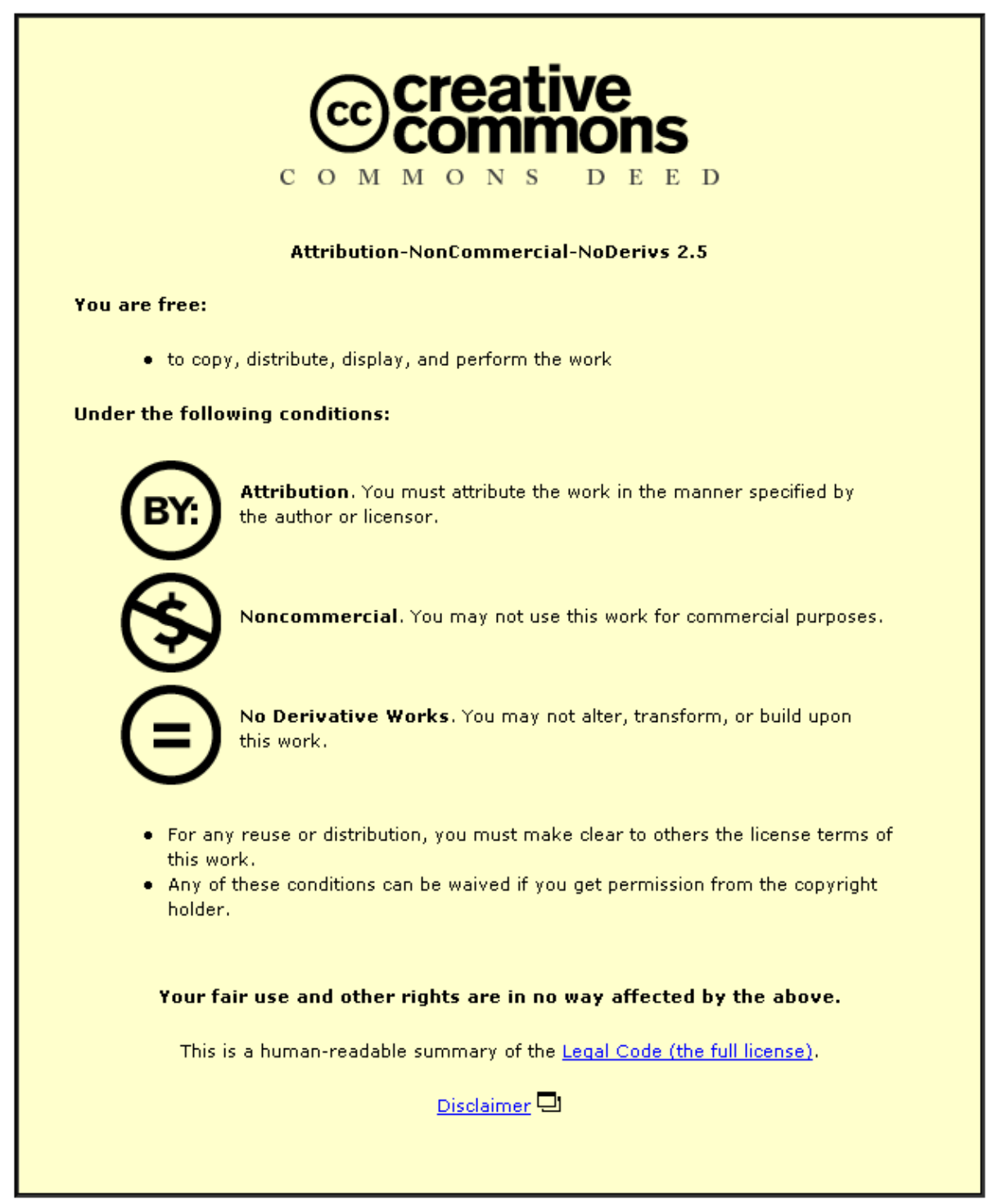

For the full text of this licence, please go to: http://creativecommons.org/licenses/by-nc-nd/2.5/ 


\title{
Micro-Raman Spectroscopy of Indentation Induced Phase Transformation in Nanozirconia Ceramics
}

\author{
Anish Paul, Bala Vaidhyanathan and Jon Binner \\ Department of Materials, Loughborough University, Loughborough, UK, \\ LE11 3TU
}

\begin{abstract}
Micro-Raman spectroscopy has been employed as an effective technique to determine the phase transformations in nanostructured yttria stabilised zirconia (YSZ) ceramics with different yttria content. Samples have been prepared with varying mean grain sizes by a slip casting route followed by a microwave assisted two-step sintering cycle starting with aqueous nanozirconia suspensions. Indents were generated using a Vickers pyramidal indenter at different loads and the resulting phase transformations were mapped using micro-Raman spectroscopy. The results were compared to those of a commercial submicron 3YSZ. The amount of transformation was found to be much lower for nanozirconia compared to the submicron zirconia with similar yttria content.
\end{abstract}

Keywords: Micro-Raman spectroscopy, nanozirconia, two-step sintering

\section{Introduction}

Zirconia has three well defined polymorphs, monoclinic, tetragonal and cubic; the former is stable at room temperature whilst the other two are stable at temperatures above $1000^{\circ} \mathrm{C} .^{1}$ The tetragonal and cubic phases can be stabilised at room temperature by doping with appropriate amounts of $\mathrm{CaO}, \mathrm{MgO}, \mathrm{Y}_{2} \mathrm{O}_{3}$ and $\mathrm{CeO}_{2}$. Full or partial stabilisation is required because the martensitic transformation from tetragonal to monoclinic involves a $3-5 \%$ volume change when the sintered body is cooled and this induces cracks causing components to shatter on cooling. ${ }^{2}$ Zirconia nanoparticles, however, have a size dependent phase stability; when the particle size is below a critical limit, they exist in their metastable tetragonal polymorph. ${ }^{3}$ This provides the possibility of stabilising the tetragonal phase in YSZ with lower amounts of stabiliser than for conventional, submicron ceramics; in turn helping to reduce the cost of zirconia based nanopowders. 
Micro-Raman spectroscopy is an important technique enabling fundamental molecular vibrations to be measured. These vibrations shift the wavelength of a small fraction of the light, typically from a laser that strikes the substance, forming sharp, well resolved bands. The Raman shift is different for the monoclinic and tetragonal phases resulting in separate peaks. The intensity of the peaks is proportional to the amount of each phase and this in turn, can be used for quantitative phase analysis of materials. The technique is non-contact, non-destructive and requires no special preparation or manipulation of the sample. It is a rapid method compared to techniques such as X-ray diffraction (XRD) and can be used to obtain both qualitative and quantitative data. Unlike XRD a micro-Raman spectrum can be collected from a very small area $\left(\sim 1 \mu^{2}\right)$ yielding high spatial resolution. In the confocal probe configuration, Raman spectrometers can obtain information from the surface of a sample inwards, enabling gradients to be assessed. Micro-Raman mapping is a technique in which a number of spectra are collected from a specific area to obtain information about the spatial distribution of different materials and/or different phases. A large number of spectra are collected from an area under investigation with the help of computer-controlled stepping motors and are then integrated with the help of a software to yield a two dimensional map of the area, showing different materials, different phases, or stress levels. Spectroscopes equipped with confocal lenses enable quasi-three dimensional mapping.

There are a number of reports in the literature concerning the use of Raman microscopy for analysing zirconia based ceramics, ${ }^{4,5,6,7,8}$ for example, it has been employed to find the different $\mathrm{ZrO}_{2}$ phases present at various temperatures, both above and below the phase transition temperature, $9,10,11,12$ and to study pressure induced phase transitions. ${ }^{13}$ Quantitative data may be obtained ${ }^{11,12,14,15,16}$ allowing, for example, examination of Vickers indentation induced phase transitions, ${ }^{17,18}$ characterization of wear surfaces, ${ }^{19}$ calculation of residual and mechanical stresses in bulk materials including zirconia toughened alumina ${ }^{20,21}$ and also for analysing fracture surfaces. ${ }^{22}$ Micro-Raman mapping has been used to map the locations of the phases present, for example, to study the phase changes near indent corners. ${ }^{23}$ The technique has also been used recently for a study of the phase changes and stress distributions occurring in zirconia toughened alumina femoral heads. ${ }^{24}$

In this work, confocal micro-Raman spectroscopy was used as an effective technique for studying the spatial distribution of indentation induced phase transformations in nanostructured zirconia ceramics with different yttria contents. Recording the spectra 
with a spatial resolution of $\sim 1 \mu \mathrm{m}^{2}$, the results have been compared with those of a submicron zirconia sample prepared from a commercial powder. No quantitative calculations were made; the aim was to investigate the potential grain sizedependent stabilization of nanozirconia and its consequences.

\section{Experimental}

The nanozirconia samples used in the present study were prepared by slip casting. As received aqueous suspensions of nano yttria partially stabilised zirconia powders containing 0, 1.5, 2 and 3 mol\% yttria and with $\sim 5$ vol\% solids content (MEL Chemicals, Manchester, UK), were concentrated using a patented technique ${ }^{25,26}$ to $\sim 20$ vol\% solid content and slip cast into $15 \mathrm{~mm}$ dia. plaster of Paris (Millecast, Lafarge Prestia, Mériel, France) moulds. To ensure there were no agglomerates present prior to slip casting, the suspensions were exposed to ultrasound for $3 \mathrm{~min}$ whilst being kept cool in a water bath. The required amount of suspension was transferred slowly into the mould cavity to ensure that no air bubbles became trapped in the suspension during transfer. After casting, the mould and casting were left under laboratory conditions $\left(20-25^{\circ} \mathrm{C}\right)$ for up to $72 \mathrm{~h}$ to allow an initial degree of drying, after which the samples were removed from the mould and placed on a Teflon sheet to allow unrestricted shrinkage for a further drying period of $48 \mathrm{~h}$. Once fully dry, the samples were heated to $700^{\circ} \mathrm{C}$ for $2 \mathrm{~h}$ at $0.5^{\circ} \mathrm{C} \mathrm{min}^{-1}$ to remove the organics. Sintering was subsequently performed via a two-step sintering cycle using a microwave/radiant hybrid furnace (C-Tech Innovation Limited, Capenhurst, UK). Previous work had shown that this approach was capable of limiting the grain growth. ${ }^{26}$ The samples were heated to a high initial temperature, T1, for 6 seconds and then cooled down to a slightly lower temperature, T2, and held for sufficient period of time to allow complete densification. The hybrid furnace could be operated in either pure radiant or hybrid microwave / radiant mode. The microwave frequency was $2.45 \mathrm{GHz}$; up to $2 \mathrm{~kW}$ of microwave power was available. In the present work a fixed level of $600 \mathrm{~W}$ of microwaves was used throughout the sintering cycle, with the amount of radiant power being varied to yield the desired temperature-time profile. The temperature was measured and controlled using an optical fibre thermometer (Accufiber Model 100, Luxtron Corp, Santa Clara, California, USA). Samples with different mean grain sizes were prepared by varying the sintering conditions, Table 1. More details about sample preparation can be found elsewhere. ${ }^{26,27}$ Nano OYSZ samples were prepared using conventional single step sintering (Carbolite UK Ltd., 
Sheffield, UK). For comparison, samples with a submicron grain size were prepared using a commercial 3YSZ powder, grade 3YSB-C (Tosoh Corporation Europe, Amsterdam, Netherlands). These samples, which measured $10 \mathrm{~mm}$ in diameter, were prepared by dry pressing at $180 \mathrm{MPa}$ and subsequently sintered using a conventional, single stage sintering cycle (Carbolite UK Ltd., Sheffield, UK) at $1500^{\circ} \mathrm{C}$ for $2 \mathrm{~h}$ using a heating/cooling rate of $2^{\circ} \mathrm{C} \mathrm{min}^{-1}$.

Table 1 Sintering conditions for the preparation of samples in this study

\begin{tabular}{|l|c|c|c|c|}
\hline Sample & $\mathrm{T} 1 /{ }^{\circ} \mathrm{C}$ & $\mathrm{T} 2 /{ }^{\circ} \mathrm{C}$ & $\begin{array}{c}\text { Microwave } \\
\text { power } / \mathrm{W}\end{array}$ & $\begin{array}{c}\text { Time at T2/ } \\
\mathrm{h}\end{array}$ \\
\hline Nano 0YSZ & - & 1125 & - & 10 \\
\hline Nano 1.5YSZ & 1150 & 1000 & 600 & 5 \\
\hline Nano 2YSZ & 1150 & 1050 & 600 & 5 \\
\hline Nano 3YSZ & 1150 & 1050 & 600 & 5 \\
\hline Submicron & - & 1500 & - & 2 \\
\hline
\end{tabular}

The density of the sintered samples was determined using the Archimedes method with water as the displacing medium. The theoretical density was taken as $6.05 \mathrm{~g}$ $\mathrm{cm}^{-3}$ for all the yttria containing samples and as $5.84 \mathrm{~g} \mathrm{~cm}^{-3}$ for the pure monoclinic zirconia (OYSZ). For polishing and grain size determination, the sintered samples were all mounted in epoxy resin (Epofix, Struers Ltd., Solihull, UK) and polished using a semi-automatic polishing machine (TegraPol-25, Struers Ltd., Solihull, UK) with successively finer diamond polishing discs. The final polish used a $0.04 \mu \mathrm{m}$ colloidal silica suspension (OP-S, Struers Ltd., Solihull, UK). After polishing the nano samples were thermally etched for $6 \mathrm{~min}$. at the second step sintering temperature (T2). This prevented unwanted grain growth during thermal etching. The commercial submicron samples were thermally etched for the same duration at $1350^{\circ} \mathrm{C}$. To determine the grain size, micrographs were taken using a LEO 1530VP field emission gun scanning electron microscope (LEO Elektronenskopie $\mathrm{GmbH}$, Oberkochen, Germany) at different magnifications. The grain size was determined using the linear intercept method (ASTM E 112-96), the two dimensional grain size being converted to three dimensional using a conversion factor of $1.56 .{ }^{28}$ At least three micrographs and a total of 300 grains were evaluated to determine the mean grain size for each sample batch.

The indentation toughness of the samples was measured after polishing, but before thermal etching. The indents for the toughness measurements and subsequent 
micro-Raman studies were created using a Mitutoyo AVK-C2 Vickers hardness tester (Mitutoyo Corporation, Kawasaki, Japan) via applying a $10 \mathrm{~kg}$ load. The load was increased to $20 \mathrm{~kg}$ and then to $30 \mathrm{~kg}$ for the nano $1.5 \mathrm{YSZ}$ samples and the indentation toughness was calculated using the formula reported by Anstis et al. ${ }^{29}$

The micro-Raman spectra were recorded using a LabramHR spectrometer (Horiba Jobin Yvon SAS, Villeneuve d'Ascq, France) in the confocal configuration. The spectrometer was equipped with a liquid nitrogen cooled CCD detector and had two objective lenses, 10x and 50x magnification. The optical microscope of the microRaman device was connected to a video monitor that allowed specific areas on the sample surface to be selected for analysis. The movement of the sample stage was controlled using a computer driven stepping motor. The spectroscope was equipped with argon (wavelength $514 \mathrm{~nm}$ ) and helium-neon (wavelength $632.8 \mathrm{~nm}$ ) lasers. The latter was used in the present study to excite the sample and the laser power used was $20 \mathrm{~mW}$. The spectra were collected from 100 to $800 \mathrm{~cm}^{-1}$; spectrum integration time was $60 \mathrm{~s}$ and it was averaged over two successive measurements. When mapping was performed the range was reduced to 100 to $350 \mathrm{~cm}^{-1}$ since it covered the most important peaks corresponding to the monoclinic and tetragonal phases and the integration time was reduced to $5 \mathrm{~s}$. The spatial resolution of the equipment was $\sim 1 \mu \mathrm{m}$.

\section{Results and Discussions}

Only samples with a density of $>99.0 \%$ were used in the present study except for the OYSZ sample, where the maximum density obtained was $\sim 98 \%$ of theoretical. Representative microstructures of the nano and submicron 3YSZ samples are shown in Figure 1. 


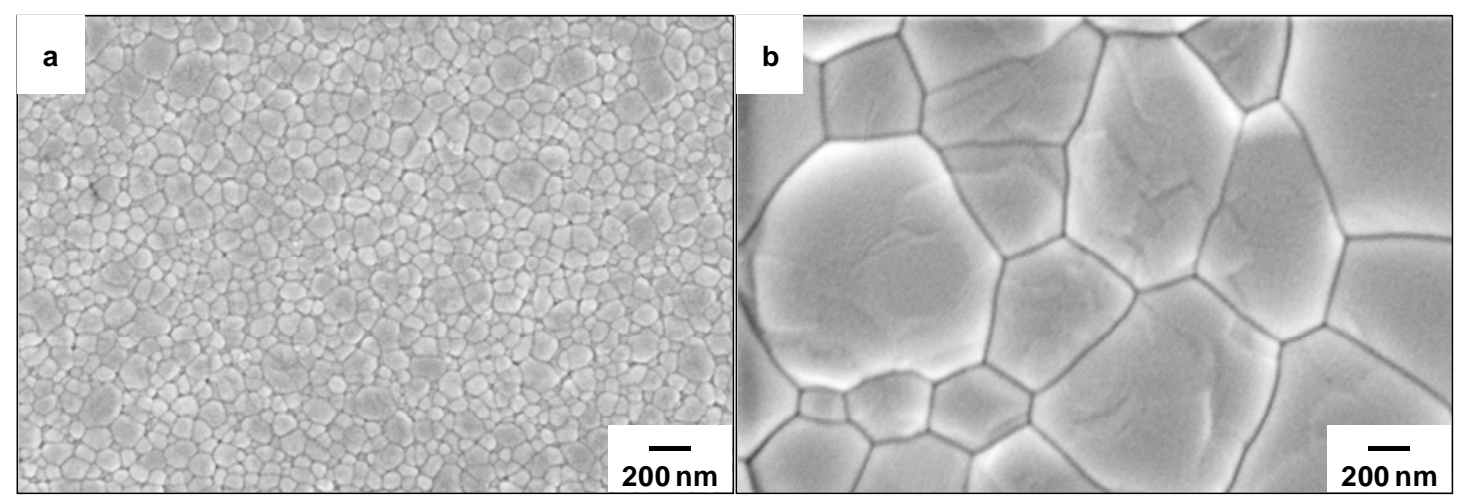

Figure 1 Representative microstructures of (a) nano 3YSZ and (b) submicron 3YSZ used in the present study. Both samples were $>99.0 \%$ of theoretical density and had mean grain sizes of $130 \mathrm{~nm}$ and $520 \mathrm{~nm}$ respectively.

A detailed study if the variation in hardness and indentation toughness with grain size for samples with different yttria contents is reported elsewhere. ${ }^{30}$ The samples which showed the maximum indentation toughness for each composition were selected for the micro-Raman study. Table 2 summarises the mean grain size, density, hardness and toughness of these samples.

Table 2 Mean grain size, density, hardness and toughness of the samples selected for micro-Raman study.

\begin{tabular}{|l|c|c|c|c|}
\hline \multicolumn{1}{|c|}{ Sample } & $\begin{array}{c}\text { Mean } \\
\text { grain size } \\
/ \mathrm{nm}\end{array}$ & $\begin{array}{c}\text { Density } \\
( \pm 0.1 \%) \\
/ \% \mathrm{TD}\end{array}$ & $\begin{array}{c}\text { Hardness / } \\
\text { GPa }\end{array}$ & $\begin{array}{c}\text { Indentation } \\
\text { Toughness }^{*} \\
\text { MPa m }^{1 / 2}\end{array}$ \\
\hline Nano 0YSZ & 230 & 98.1 & $9.2 \pm 0.08$ & $2.5 \pm 0.28$ \\
\hline Nano 1.5YSZ & 190 & 99.9 & $11.3 \pm 0.07$ & $14.5 \pm 0.10$ \\
\hline Nano 2YSZ & 250 & 99.5 & $12.2 \pm 0.35$ & $7.6 \pm 0.51$ \\
\hline Nano 3YSZ & 130 & 99.8 & $13.6 \pm 0.26$ & $3.9 \pm 0.15$ \\
\hline Submicron & 520 & 99.8 & $13.0 \pm 0.42$ & $4.6 \pm 0.34$ \\
\hline
\end{tabular}

*Obtained using a $10 \mathrm{~kg}$ load except for the nano $1.5 \mathrm{YSZ}$ which required $30 \mathrm{~kg}$ load to develop radial cracks.

The $10 \mathrm{~kg}$ indentations on the submicron $3 \mathrm{YSZ}$ and nano $1.5 \mathrm{YSZ}$ samples are shown in Figure 2; the absence of radial cracks for the nano sample is clearly evident. Nano 1.5YSZ and 2YSZ had a lower hardness than the submicron 3YSZ whereas nano 3YSZ displayed slightly higher hardness, Table 2. 


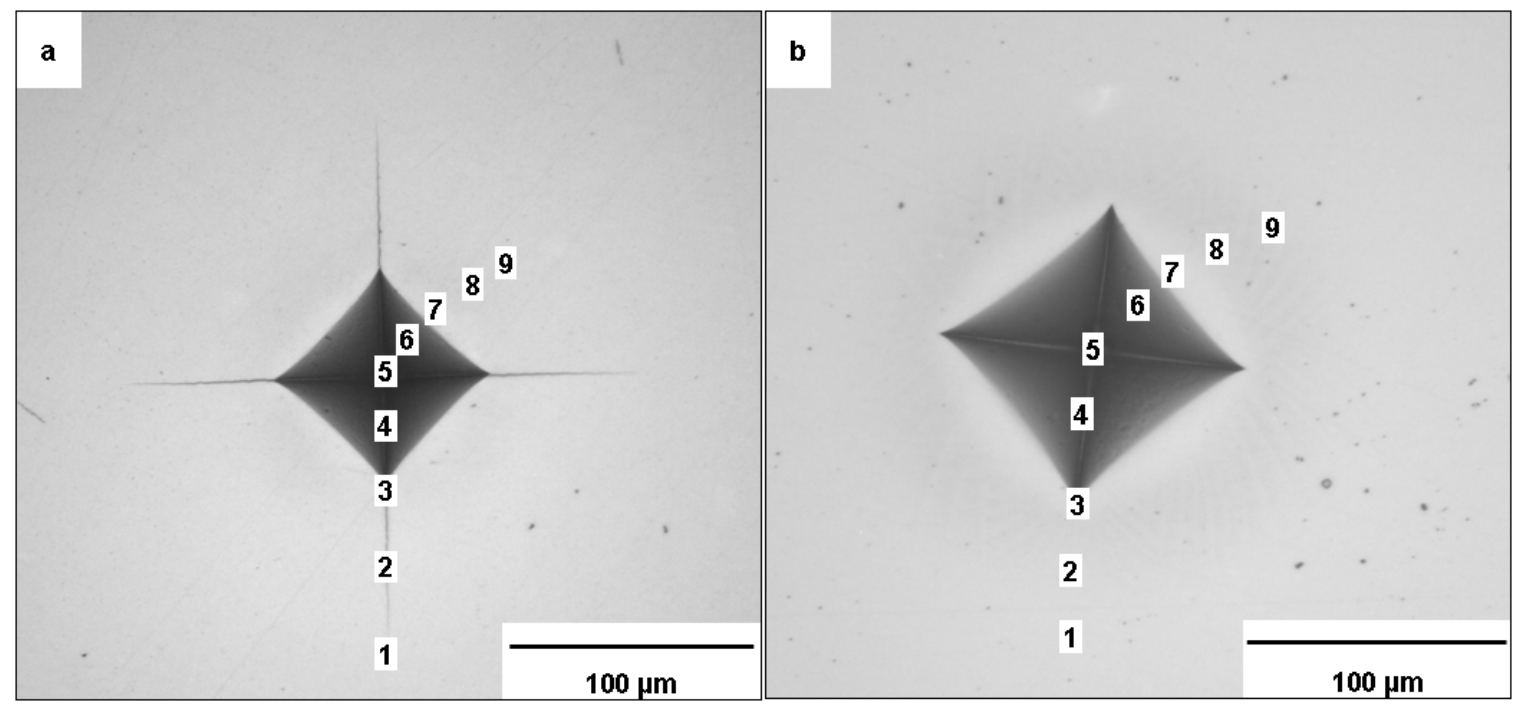

Figure 2 Optical microscopic image of the indent created on (a) submicron and (b) nano $1.5 \mathrm{YSZ}$ at $10 \mathrm{~kg}$ load. The locations from where the micro-Raman spectra were taken are numbered 1-9.

The micro-Raman spectra were recorded at a number of locations as indicated in Figure 2; the distance between the points 7,8 and 9 were $\sim 20 \mu \mathrm{m}$ each. The microRaman spectra of the submicron $3 Y S Z$, nano OYSZ, nano $2 Y S Z$ and nano $3 Y S Z$ listed in Table 2 are shown in Figure 3 Micro-Raman spectra recorded from positions 1-9 for 4 different samples; all the indents were created using a $10 \mathrm{~kg}$ load. 

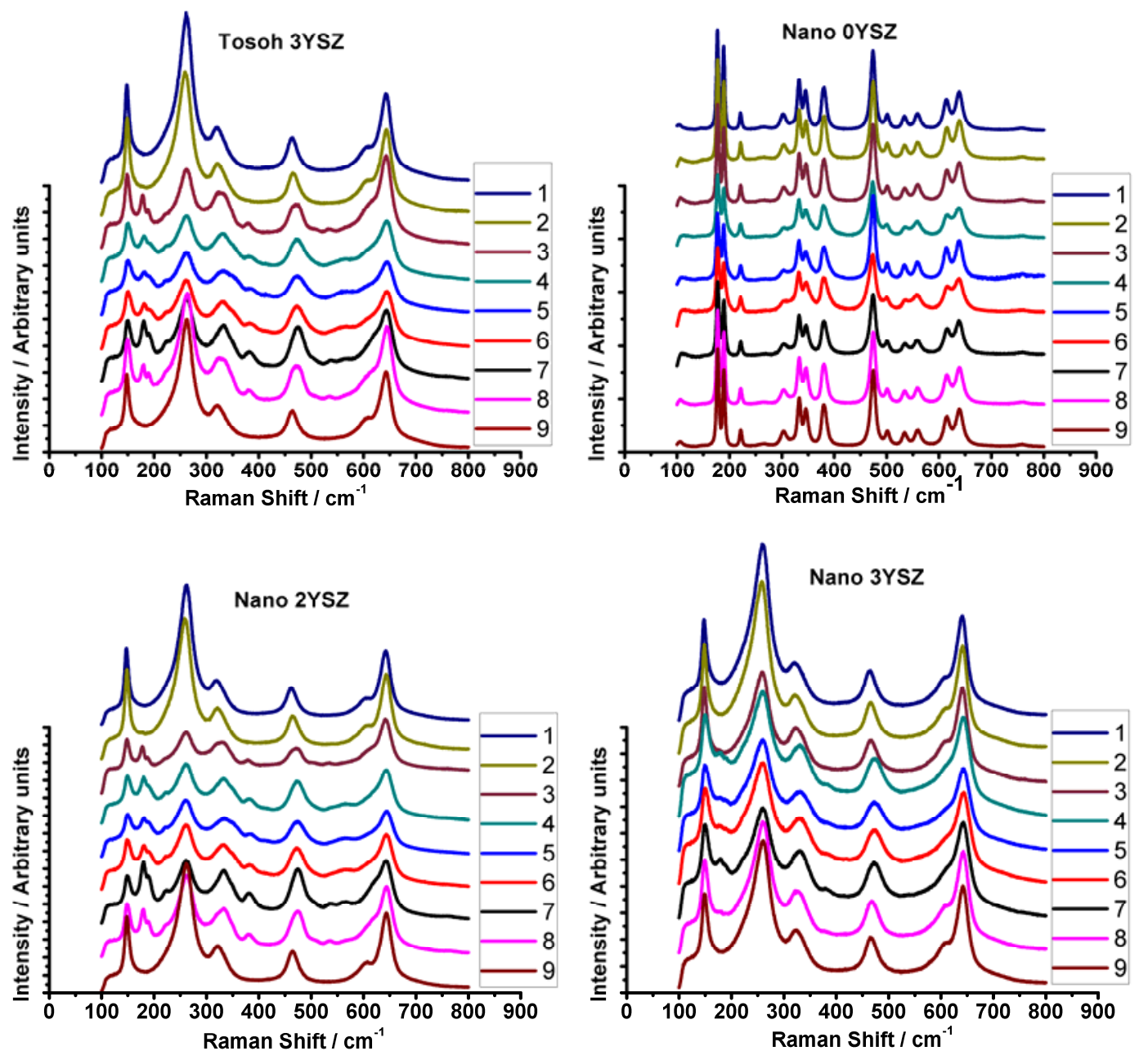

Figure 3 Micro-Raman spectra recorded from positions 1-9 for 4 different samples; all the indents were created using a $10 \mathrm{~kg}$ load.

All the peaks for the nano OYSZ correspond to the monoclinic phase; this was expected since XRD (not shown here) confirmed that this composition consisted entirely of this phase. The indentation toughness of this material was also the lowest because of the absence of any transformation toughening. The micro-Raman spectra for the submicron sample showed monoclinic peaks (monoclinic doublet at 188 and $191 \mathrm{~cm}^{-1}$ ) in most of the locations in and around the indent and the crack. From the peak intensities it can be observed that maximum phase transformation has occurred at the indent corners and near the indent edges (positions 3 and 7). These observations are in agreement with the results reported by Reece et al., ${ }^{31}$ where they observed maximum transformation away from the apex of the indentation impression for a highly transformable Ce-TZP ceramic. Any transformation below a few micrometers from the surface were not detected since the equipment was used in the confocal probe configuration. Previous studies in this area employed a non-confocal 
approach, ${ }^{31,32,33}$ which can lead to the penetration of laser beam up to a depth of 40 $\mu \mathrm{m}$, leading to Raman signals being collected from well below the surface layer altering the peak intensities. ${ }^{34}$

Comparing the micro-Raman spectra of the nano 3YSZ with the submicron 3YSZ it is apparent that the intensity of the monoclinic peaks were much smaller for the nanosample. This suggested that less transformation had occurred for the latter even though the yttria contents were the same, presumably due to the much finer grain size. The reduction in transformation will have reduced the ability for crack suppression and hence resulted in less transformation toughening, explaining the slightly lower toughness values obtained for the nano $3 Y S Z$ compared to the submicron 3YSZ. In the case of the nano 2YSZ, the monoclinic peak intensities were found to be higher than those of both the nano and submicron $3 Y S Z$, indicating a higher amount of phase transformation and hence a higher indentation toughness.

Figure 4 reveals an indent generated in the nano $1.5 \mathrm{YSZ}$ using a $30 \mathrm{~kg}$ load; although cracks were formed at the indent corners, they were very short compared to those in the submicron 3YSZ, Figure 2a, and other yttria containing compositions indented at the reduced load of $10 \mathrm{~kg}$. Figure 4 also highlights the stress patterns around the indent. Reece et al., ${ }^{31}$ suggested that such surface patterns were a combination of the effect of elastic relaxation during indenter unloading and dilatation associated with phase transformation. Kaliszewski et al., ${ }^{33}$ reported that during indenting the martensitic transformation occurred in a localised zone around the indentation, giving rise to stress fields in the surrounding material due to volume misfit. Since the stress fields were visible even after the removal of the indenter, they assumed that the indentation-induced deformation was accommodated by a permanent, non-elastic mechanism. Bravo-Leon et al. ${ }^{35}$ also reported similar indentation behaviour for nano $1.5 \mathrm{YSZ}$ though the latter was only $98 \%$ dense. They suggested that the slightly projecting lines surrounding the indentation area were the lines of maximum shear stress. 


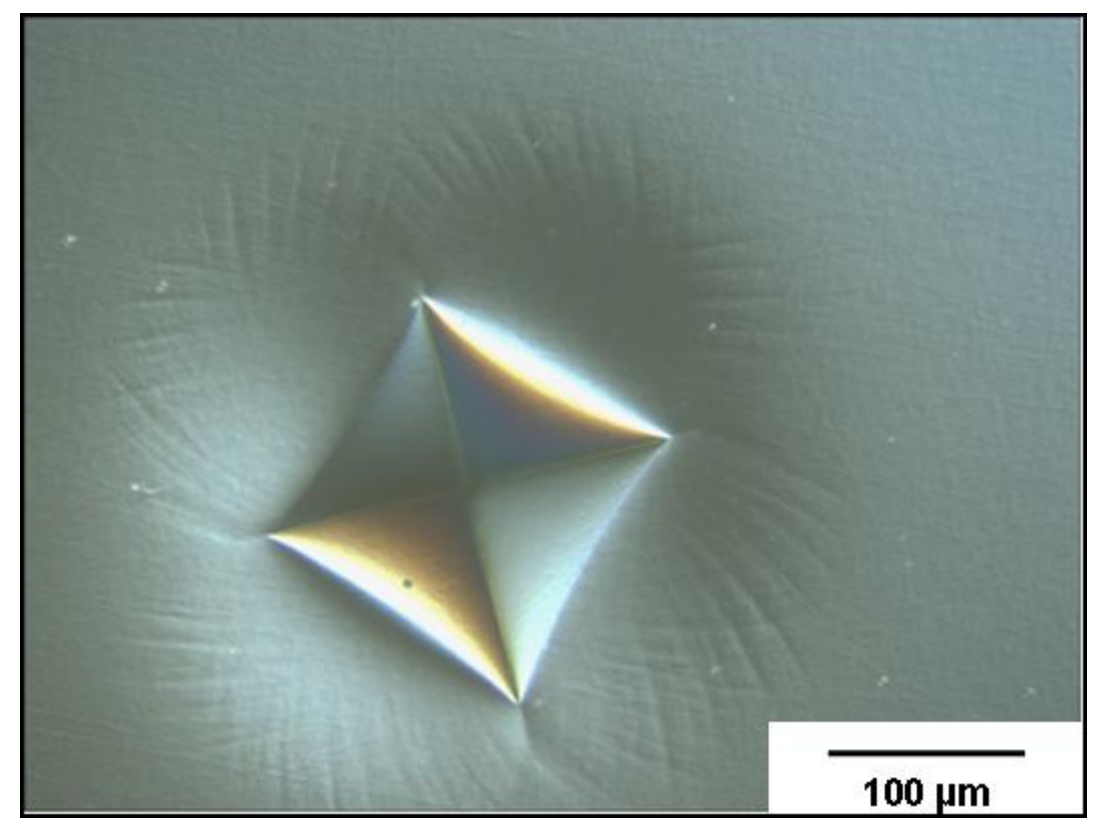

Figure 4 Differential interference contrast (DIC) microscopic image of an indent on the nano 1.5YSZ sample. The indentation load was $30 \mathrm{~kg}$.

The micro-Raman spectra recorded for the nano 1.5YSZ sample indented at loads of 10,20 and $30 \mathrm{~kg}$ are shown in Figure 5 Micro-Raman spectra of the nano1.5YSZ sample after indenting at 10,20 and $30 \mathrm{~kg}$ load.

, it can be observed that the intensity of the monoclinic peaks are higher than those of all other yttria containing compositions at the same load, indicating a greater amount of phase transformation. This increased phase transformation resulted in higher indentation toughness for the nano 1.5YSZ, Table 2. A comparison of the spectra obtained after indenting at $20 \mathrm{~kg}$ and $30 \mathrm{~kg}$ revealed that there was at least some monoclinic phase at all locations in and around the indent, with more monoclinic being present after use of the $30 \mathrm{~kg}$ load. This not only illustrated an increase in phase transformation with increased load, but also an increase in the size of the transformation zone around the indent. 

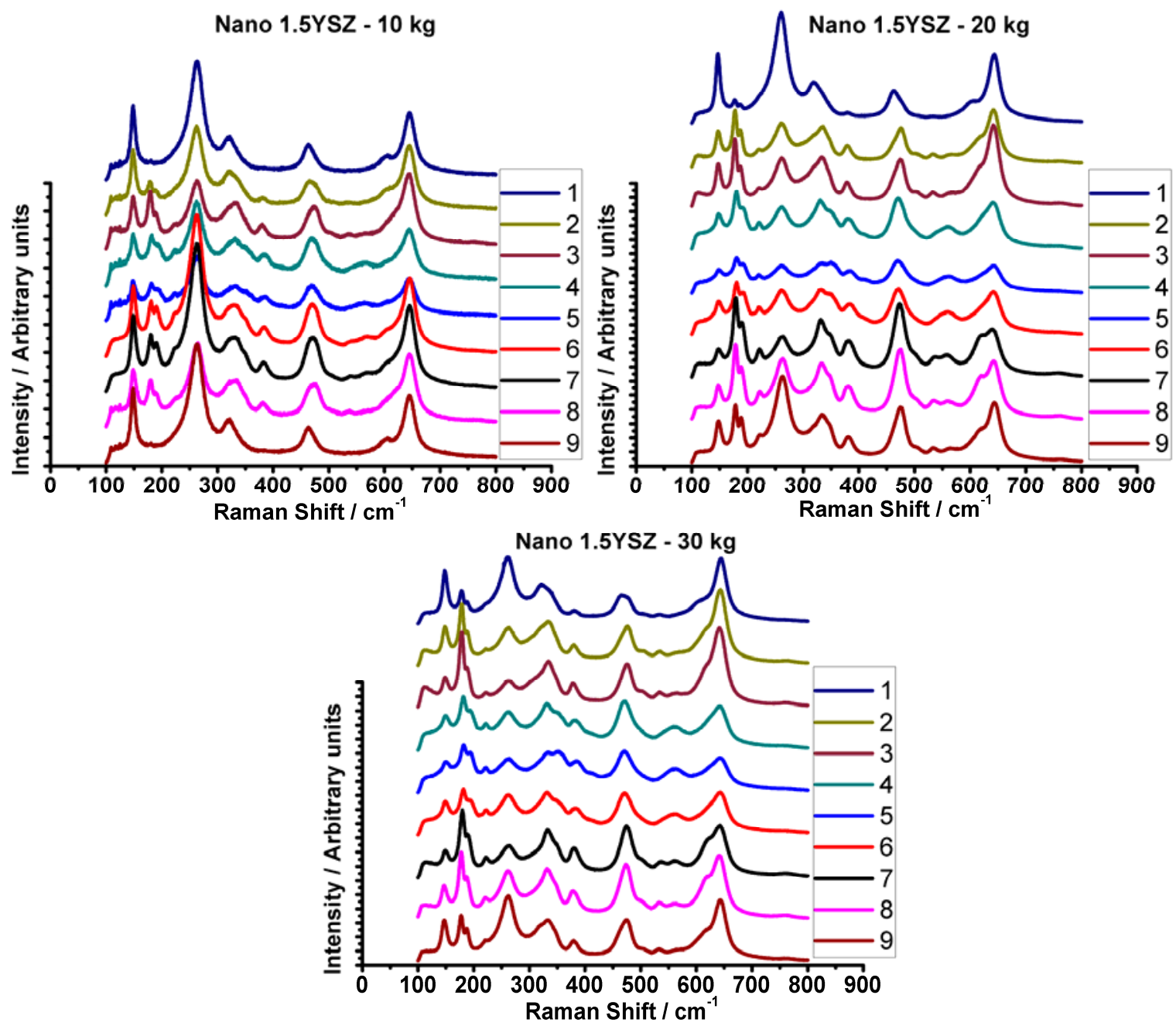

Figure 5 Micro-Raman spectra of the nano1.5YSZ sample after indenting at 10, 20 and $30 \mathrm{~kg}$ load.

The nano $1.5 \mathrm{YSZ}$ sample indented using the $30 \mathrm{~kg}$ load was used to map the phase transformations in and around the indent, Figure 6 . It can be observed that there was a considerable amount of phase transformation around the indent; the presence of monoclinic phase close to the propagating cracks is also clearly distinguishable. One would expect the maximum phase transformation directly below the indent, however the dilatation associated with the phase transformation enhances the residual tensile forces which in turn enhances subsurface transformation and transformation around the indentation impression giving rise to higher monoclinic peak intensities. ${ }^{31}$ The monoclinic peak intensities in the indent are not influenced by the presence of subsurface monoclinic peaks, since the mapping is done using the confocal probe configuration. Thus confocal micro-Raman spectroscopy proved to be a very powerful technique for mapping the phase distribution of zirconia, which is not possible with other techniques such as XRD. It was also observed from the micro- 
Raman mapping that the nano $1.5 \mathrm{YSZ}$ samples displayed the maximum amount of transformation among all the compositions studied in the present work explaining the superior indentation toughness displayed by this composition.

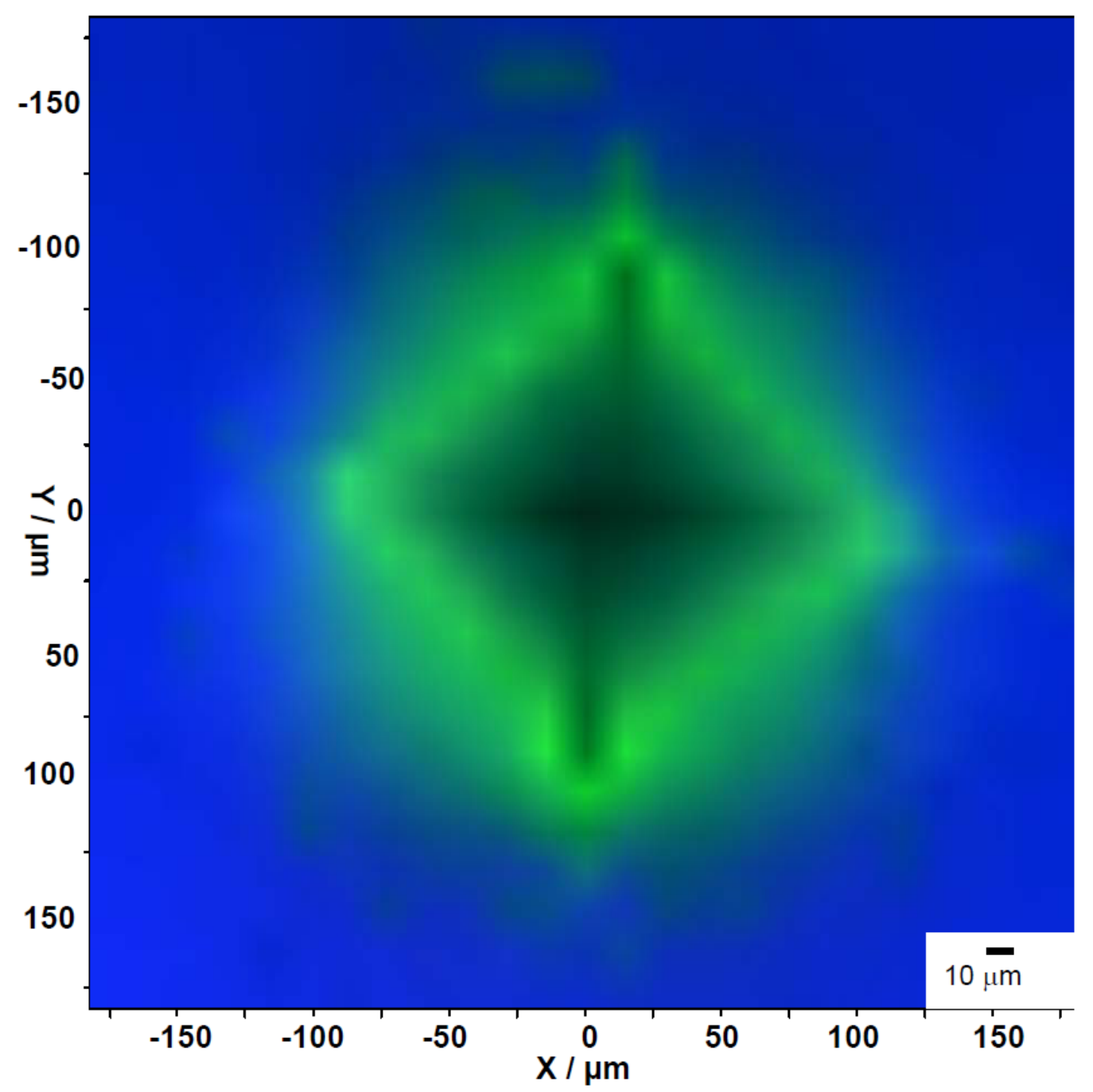

Figure 6 Micro-Raman mapping of the indentation induced phase transformation for a $30 \mathrm{~kg}$ indented nano 1.5YSZ sample. The green colour represents the presence of the monoclinic phase.

\section{Conclusions}

Confocal micro-Raman spectroscopy and mapping has been employed successfully to study the spatial distribution of indentation induced phase transformations in nano zirconia with different yttria contents. The high spatial resolution achievable with the technique enabled the mapping of the transformed monoclinic phase in and around the cracks. No tetragonal peaks were observed for the nano OYSZ sample after 
indentation as expected which resulted in the lowest toughness for these materials. The monoclinic peak intensity for the nanozirconia ceramics decreased as the yttria content increased from $1.5 \mathrm{~mol} \%$ to $3 \mathrm{~mol} \%$. The intensity of the transformed monoclinic peaks were found to be directly related to the indentation toughness of the materials. The monoclinic intensity was found to be reduced for the nano 3YSZ sample compared with the submicron 3YSZ; this is believed to be due to the increased phase stability of the former. The results of the mapping also confirmed that maximum transformation occurred in an area around the indent, not on a surface layer directly below it. 
References

1 R. H. J. Hannink and M. V. Swain, Annu. Rev. Mater. Sci., 1994, 24, 359-408.

2 R. H. J. Hannink, P. M. Kelly and B. C. Muddle, J. Am. Ceram. Soc., 2000, 83 (3), 461-487

3 R. C. Garvie, J. Phys. Chem., 1965, 69, 1238 - 1243.

4 C. M. Philippi and K. S. Mazdiyasni, J. Am. Ceram. Soc., 1971, 54, 254-258.

5 V. K. Keramidas and W. B. White, J. Am. Ceram. Soc., 1974, 57, 22-24.

6 J. C. Hamilton and A. S. Nagelberg, J. Am. Ceram. Soc., 1984, 67, 686-690.

7 M. A. Krebs and R. A. Condrate Sr., J. Am. Ceram. Soc., 1982, 65, C144-C145.

8 A. Fienberg and C. H. Perry, J. Phys. Chem. Solids, 1981, 42, 513-518.

9 M. Ishigame and T. Sakurai, J. Am. Ceram. Soc., 1977, 60, 367-369.

10 C. H. Perry, D. W. Liu and R. P. Ingel, J. Am. Ceram. Soc., 1985, 68, C184-

C187.

11 C. G. Kontoyannis and G. Carountzos, J. Am. Ceram. Soc., 1994, 77, 2191-2194.

12 J. A. M. Tabares and M. J. Anglada, J. Am. Ceram. Soc., 2010, 93, 1790-1795.

13 B. Alzyab, C. H. Perry and R. P. Ingel, J. Am. Ceram. Soc., 1987, 70, 760-765.

14 D. R. Clarke and F. Adar, J. Am. Ceram. Soc., 1982, 65, 284-288.

15 T. Hirata, E. Asari and M. Kitajima, J. Solid State Chem., 1994, 110, 201-207.

16 B. K. Kim, J .W. Hahn and K. R. Han, J. Mater. Sci. Lett., 1997, 16, 669-671.

17 G. A. Gogotsi, P. Metall. Met. Ceram., 1999, 38, 186-192.

18 G. A. Gogotsi and E. E. Lomonova, Ind. Ceram., 2000, 41, 191-195.

19 B. Basu, R. G. Vitchev, J. Vleugels, J. P. Celis and O. Van Der Biest, Acta.

Mater., 2000, 48, 2461-2471.

20 Q. Ma and D. R. Clarke, J. Am. Ceram. Soc., 1994, 77, 298-302.

21 G. Pezzotti, J. Raman. Spectr., 1999, 30, 867-875.

22 C. A. Leach, J. Mater. Sci., 1989, 24, 1380-1382.

23 M. Bowden, G. D. Dickson, D. J. Gardiner and D. J. Wood., J. Mater. Sci., 1993, 28, 1031-1036.

24 G. Pezzotti, K. Yamada, S. Sakakura and R. P. Pitto., J. Am. Ceram. Soc., 2008, 91, 1199-1206.

25 J. Binner, M. I. Santacruz, and K. Annapoorani., Method for Concentrating

Nanosuspensions. International patent application Publ. No. WO 2006/136780 A2, Publ. Date December 28, 2006.

26 J. Binner, K. Annapoorani, A. Paul, I. Santacruz and B. Vaidhyanathan, J. Eur.

Ceram. Soc., 2008, 28, 973-977.

27 J. Binner and B. Vaidhyanathan, J. Eur. Ceram. Soc., 2008, 28, 1329-1339. 
28 M. I. Mendelson, "Average grain size in polycrystalline ceramics", J. Am. Ceram. Soc., 52, 443 (1969).

29 G. R. Anstis, P. Chantikul, B. R. Lawn and D. B. Marshall, J. Am. Ceram. Soc., 1981, 64, 533-538.

30 J. Binner, B. Vaidhyanathan, A. Paul, K. Annaporani and B. Raghupathy,

"Compositional effects in nanostructured yttria partially stabilized zirconia", Int. J.

Appl. Ceram. Technol., 1-17, 2010, DOI:10.1111/j.1744-7402.2010.02503.x

31 M. J. Reece, P. L. Tetlow and C. Galiotis, J. Mater. Sci. Lett., 1992, 11, 575-577

32 K. Liang and K. Gu, J. Am. Ceram. Soc., 1993, 76, 3144-3146

33 M. S. Kaliszewski, G. Behrens, A. H. Heuer, M. C. Shaw, D. B. Marshall, G. W.

Dransmann, R. W. Steinbrech, A. Pajares, F. Guiberteau, F. L. Cumbrera and A.

Dominguez-Rodriguez., J. Am. Ceram. Soc., 1994, 77, 1185-1193.

34 G. Pezzotti and A. A. Porporati, J. Biomed. Optic., 2004, 9, 372-384

35 A. Bravo-Leon, Y. Morikawa, M. Kawahara and M. J. Mayo, Acta Materialia, 2002, 50, 4555-4562. 